\title{
For God's Sake: Religion and Study Abroad
}

Introduction

Guest Editors:

Timothy Lynn Elliott

Brigham Young University

William T. Hyndman III

Florida A\&M University

Nora Larkin

CAPA: The Global Education Network

Donna Scarboro

George W ashington University

\section{Michael Woolf}

CAPA: The Global Education Network.

"Religion is part of the human make-up. It is also part of our cultural and intellectual history. Religion was our first attempt at literature, the texts, our first attempts at cosmology, making sense of where we are in the universe."

-Christopher Hutchins

\section{Why a "Special Issue"}

The editors believe that religion, while an area of discussion not often at the center of study abroad, deserves to be more comprehensively included. Neglecting it can result in at least three significant problems. It raises questions about our commitment to inclusivity in study abroad; it results in significant missed educational opportunities as students observe the "foreign" culture into which study abroad drops them; and it leaves a gap in academic work related to the cultural experience of a people.

This special issue focuses on these broad questions as well as the more obvious ways in which religion and study abroad are in a dynamic relationship. Contributions explore operational issues raised by the participation of students from diverse religious faiths; examine the relationship between study abroad and faith communities which have long commitments to internationalism in one way or another; and consider ways in which the agendas of education abroad might be broadened to look at faith in paradoxical contexts, as an opportunity to understand host environments and as a threat engendered by engagement with unfamiliar worlds. Other essays engage with a core issue: how an understanding of religious issues enhances students' understanding of histories that have an impact upon contemporary reality. Students who are taught nothing of the shaping forces of religion upon the environments in which they study (including that of the U.S.A.) 
are deprived of key insights. In short, the intersections among education abroad, religious faith, and the absence of faith offer a field of potential enquiry that would enrich student learning in any number of specific contexts.

Religious belief is not a single or simple matter, as many essays demonstrate. From one perspective, faith offers an explanation for all human behavior, a grand narrative or inclusive explanation for all experience analogous to, for example, Marxism or Fascism. This may be manifested in two ways. A particular religion may be seen as one of a number of ideologies that contain a similar core of essential belief. A One-God theory, such as that proposed by George Bernard Shaw, leads broadly to a level of tolerance and respect for religious diversity: "There is only one religion though there are a hundred versions of it." The differences derive from historical or geographical contexts.

In contrast, there is the belief that a given religion represents the only admissible truth and that other religions are a form of error, apostasy, or even blasphemy. This form of faith has historically driven the persecution of disbelievers, for example in the Spanish Inquisition. It is also at the root of contemporary fundamentalism, with consequences that have altered the lives of all of us.

It is also possible, of course, to have faith in $\operatorname{God}(\mathrm{s})$ without a belief in a specific religion, and many other personalized variants are possible. In that context, a distinction between faith and organized religion is used as an implicit critique of institutions of religion, as in Mahatma Gandhi's paradox, "If it wasn't for Christians, I'd be a Christian," or in Lenny Bruce's acerbic observation, "Every day people are straying away from the church and going back to God."

In short, the question of religion raises multi-dimensional issues along a theoretical spectrum from personal belief to a profoundly significant force in geo-political reality. For students abroad, both the personal and the geo-political can be challenged and challenging, unfamiliar, confusing, exciting, and offer opportunities for learning and growth.

\section{Atheism and Agnosticism: The ideological basis of education abroad?}

Because study abroad sets out to combine formal learning with experiences in an unfamiliar location, it must embrace a diversity of attitudes and events that enable the student to see beyond their immediate environments. For this reason, religion in the form of faith-based practices and beliefs can never be allowed to crowd out all other perspectives. Atheism is also of course another form of faith, based upon the conviction that there is no dimension beyond the material world that guides and determines events. In many modern contexts, the juxtaposition of traditional faith with waves of new belief systems and the presence of non-believers makes up the tapestry that students must interpret. Atheism offers secular and material explanations of human experience without necessarily denying the political and historical significance of religion. Agnosticism, yet another angle on faith and non-believing, is a view of the world defined by doubt. What is true or not true beyond concrete and verifiable existence is a matter of conjecture and may be classified as merely speculative. Such a view is likely to be largely liberal and non-judgmental with a personalized ideological basis. 
In these terms, study abroad is academic and agnostic. It is a liberal endeavor in so far as it encourages interest in and appreciation of diverse opinions and behaviors. It recognizes that truth may be problematic and that what is known is open to interpretation. Doubt creates an environment amenable to some level of respect for global diversity and for scholarly methodologies developed outside the faith traditions.

The philosophical underpinnings of most versions of faith have the potential to conflict with these assumptions. For some students there may be barriers that make study abroad problematic at best and ill-advised at worst. In contrast, most of us who work in this field share values and assumptions that are broadly liberal and largely cosmopolitan. We encourage engagement with other peoples and places because they demonstrate different behaviors, values and thoughts, not in spite of those. These assumptions are driven by a sense that what we believe may not be the only thing worth believing: what is true or not true is not an absolute for all peoples in all seasons. This is an agnostic view of the world: ethical and intellectual uncertainty is a position of principle.

Many of us nevertheless have profound religious conviction, but those convictions tend to be pluralistic, admitting of the idea that faith can encompass many variants. This kind of inclusivity is not endorsed by all versions of faith. Almost all religions contain a grand narrative, an inclusive ideology that offers an explanation of the world. There is a kind of faith that permits inclusivity and a kind of faith that excludes inclusivity and that purports to be The Truth rather than a version of truth.

In a theoretical spectrum, liberal consensus and theological absolutism are towards the opposite ends of ideological possibilities. In international education we do not propose an exclusive set of judgments but rather suggest that the complexities of the world demonstrate the problematic nature of judgments. It is not that they cannot be made but rather that they have to be made through a filter of uncertainty.

Of course, many deeply religious students study abroad, and frequently we are insufficiently aware of the implications. In any case, students who study abroad are self-selecting. If they are committed to some form of theological absolutism they have, for the most part, been able to compromise with academic and agnostic assumptions, or they have not recognized them, or have decided that their experiences can be encompassed within their belief system.

These dynamics generate paradoxes. How is this academic position toward knowledge, based on liberal consensus, embedded in education abroad? Is the study abroad approach to religion identical to a typical academic framework that one might find in any learning community, or is it inherently different and in some ways more rich and risky?

\section{Religion and Under-Representation}

Discussions of religion and study abroad challenge the agenda to increase representation and require us to reconsider assumptions that we may have about the importance of inclusion. For the most part, whether they are aware of this or not, participants in study abroad passively or actively accept-or at least agree to participate in - a broadly inclusive view of the world. We need to be conscious of the fact that there are students for whom that view of the world, and the challenges of participating in it, are a matter worth attention and care. Is our concern with under-representation 
focused on those groups of which, given our inclusive ideology or academic arms-length attitudes, we approve? To what degree can we, or do we, actively address groups whose ideologies, whether faith-based or derived solely from disfavor for urban inclusivity, directly conflict with our own?

These considerations might also suggest an expanded agenda. Diversity is not only an objective; it is also something that we might teach, a topic relevant to many of the study abroad environments in which we function. Teaching religious diversity is an educational imperative that offers rich learning opportunities that may, for example, raise awareness of social, political, economic realities at home. What aspects of diversity do we, and do we not, teach?

Current discourse around issues of diversity in education abroad tends to focus on race as a default distinction. When applied to the realities of other countries this creates an America-centric and narrowing lens, an over-simplified and, sometimes, distorted perspective. As a consequence, the significance of religious dynamics may be given insufficient attention in our teaching agendas.

Further, religion, whether as formal association or informal belief, may be a barrier to participation in study abroad, either as an intrinsic characteristic of the faith (e.g. protecting purity of belief from "contamination") or as a consequence of the, usually unintended, messages sent in the marketing of study abroad. This is a rarely considered characteristic of under-representation and may suggest that the field is concerned with the under-representation of certain groups whose challenges we have taken to heart and not of others whose beliefs represent a challenge to academic assumptions and the accepted traits we have identified as worthy of our careful treatment and inclusion. Race, ethnicity, sexual orientation and economic status matter, in other words, in study abroad professional circles; religion much less so.

\section{The Bible as Cultural Territory}

William Tyndale's translation of the Bible into common English coincided with Gutenberg's new printing techniques, extending access to the documents that guided Christianity. Tyndale's work paved the way for the King James translation and was responsible for the first step in a process that embedded the Bible into the consciousness of the English-speaking world for at least four centuries. Other European countries, and eventually much of the so-called "New World," shaped, excused, or grounded a myriad of policies, political actions, and personal habits on these collected, ancient, translated texts.

Literature, in English and other European languages, was and is decipherable through at least two codes: the historically-situated events and figures recorded in the works, and points of biblical reference commonly understood by readers. Without at least a rudimentary knowledge of the biblical references, the work is diminished. More to the point, the society that built its assumptions on give-and-take with these textual sources is vastly more difficult to fathom without some background knowledge of the texts and their treatment over time in literature, art, philosophy, doctrine, and other manifestations of culture. The Bible is not only a critical source for literature and art. It is also at the heart of global conflicts that have shaped the world for centuries. It was interpreted to encourage historical aggressions such as the Crusades. It was used to justify slavery and, paradoxically, the struggle against slavery. It was used to justify imperialism and also inspired anti-imperialism. Jomo Kenyatta, with wit and wisdom, described the role of the Bible in the 
colonisation of Kenya: "When the missionaries arrived, the Africans had the land and the missionaries had the Bible. They taught us how to pray with our eyes closed. When we opened them, they had the land and we had the Bible." In short, the Bible offers important perspectives upon our histories.

If we want students to understand the literature and art of the European or American past, they must be taught something of the Bible and something of the remaining iconic and influential texts as the limits of education allow. Acknowledging those limits also points to the hope that we instill the values of lifelong learning. Wherever students come from and wherever else they may encounter during their years as students, we hope an ability to continue applying their knowledge and attaining new knowledge is the result. We expect, as part of our agenda, that they will continue deriving understanding from and applying critical thinking — sympathetic critical thinking ideally — to religious expression. Becoming a participating adult in society, whether local, national, or global, will demand it, and therefore, educators cannot ignore it.

The example of Shakespeare is instructive. His maturity as a writer coincides with the writing of the King James Bible. The King James Bible was written between 1604 and 1611, a period that witnessed the flowering of English rhetoric and was, arguably, the greatest period of creativity in the history of the language. These are also the years of profound creativity for Shakespeare.

Shakespeare's Hamlet is arguably his best-known work, and the best-known speech is, probably, the soliloquy "To be or not to be." People who have never read a word of Shakespeare or seen the play can recite the famous line. For them, it creates a field of emotional intensity. Without knowing the religious references that complicate Hamlet's intention to act in revenge, the reader can understand something but will miss much. An uninformed audience will also only partly understand the meaning of Shakespeare's reference to "slings and arrows of outrageous fortune." They will read "fortune" as luck rather than as a complex set of circumstances that derive from God's will. The idea of outrageous fortune also resonates with the suffering of Job. The line does not simply signify bad luck but references again the idea of a pattern of experience beyond human understanding that is unfolded through biblical exegesis over time.

In higher education, well-meaning caution about imposing dominant assumptions may lean into silence on vital matters of belief. We may run the risk of being timid about discussing ideologies, identities, beliefs and diversities with a religious basis. The fact that this is a difficult and controversial area of conversation is precisely a rationale for this edition.

\section{Religion as a Lens}

Religion may function as a filter through which experience abroad is perceived. We may wish to challenge the assumption that students see the world through some form of vaguely liberal perspective. At what point does faith impose an obligation, explicit or implicit, to convert the "foreign infidel," and how does this impact the experience abroad?

\section{Religion as a Subject to be Taught Abroad}

The study of religion in distinct national contexts could enhance the study of host nations and enable students better to understand the environment in which they are studying. Such an approach might also demonstrate the fact that "diversity" (seen as race in the default distinction of the U.S.) is 
not necessarily constructed in the same way in other national contexts. And religion could also be taught as global, trans-national phenomena-part of the ideological fractures across the globe, for example.

\section{Individual Religions and Internationalism/Study Abroad}

The Jesuits have had an international history that goes back centuries, but what of other religions and their ideological, ethical view of engagement with the world? Is internationalism/cosmopolitanism welcome or is it a threat to the integrity of faith? Do devout Christians, Jews or Muslims see education abroad as an opportunity or a threat, and what in their belief system might lead to such a view?

The field of education abroad needs to consider these issues not just "for God's sake" but for the sake of our students who deserve to understand the world in which they live. We have an obligation to go further than that which can be seen and ask questions that demonstrate the functioning of the immutable upon the fabric of our existence. 